Patients with ulcerative pulmonary lesions should not be allowed to expectorate in any place, either out or in doors, except in vessels containing suitable disinfectants.

Heat, solution of corrosive sublimate, 1 in 500 (acidulated with tartaric acid to prevent the coagulation of albumin), or carbolic acid, 1 in 10, will promptly destroy the tubercle bacillus.

Large, well-glazed cuspidors with perpendicular sides should be used (surrounded, if necessary, by screens) and cleaned daily, would protect public buildings and homes. Public conveyances to be protected by suitable vessels filled with sawdust, dampened with a 1 in 250 bichlorid solution. Patients with ulcerative pulmonary lesions should carry a small, wide-necked, glass-stoppered bottle containing a small quantity of the bichlorid solution for a pocket cuspidor, to be used only when out of reach of floor cuspidors. Handkerchiefs costing not over one-eighth of a cent apiece could be carried, in an emergency, and burned after using.

Patients should be instructed to rinse out their mouths frequently with warm water containing a little essence of wintergreen. This precaution to be attended to before eating, for the protection of the patient, and after expectorating, for the protection of others as well. Kissing should always be prohibited. It has been estimated that a patient in the ulcerative stage of pulmonary tuberculosis lives about two years. During this period he is a constant source of danger to his family and a menace to society. At a cost of not exceeding $\$ 50$ and a little trouble, his sputum could be destroyed and his family largely protected from infection. Latent tuberculosis needs no precautions.

For the poor, hospitals especially designed for consumptives, and for their exclusive use, should be provided by the State as a matter of humanity, economy, and protection to the public health. The watchword should be, isolation for the patient who can not or will not be governed by the necessary sanitary regulations.

The disinfection of rooms and houses in which patients with ulcerative lesions live, or have lived, within two years, is a matter of vital concern. For this reason alone, tuberculosis should be classed by law with the infectious diseases, and be placed under the supervision of bureaus of health.

The Assembly of this Commonwealth now provides for the supervision by health officials of ten conta. gious and infectious diseases, viz., smallpox, diphtheria, scarlatina, typhoid fever, typhus fever, yellow fever, cerebro-spinal fever, Asiatic cholera, relapsing fever and leprosy.

The last two diseases in this list are so rare as to be almost a medical curiosity, yet were added to the list only last year; and an infectious and contagious disease which is the direct and primary cause of more deaths (14 per cent.) than all of the above ten, with measles and pertussis included, was omitted.

Ventilation is a much neglected measure of prevention. It has been estimated that each adult individual requires 3,000 cubic feet of fresh air per hour. In a room containing 1,000 cubic feet the air should be changed three times an hour to prevent the carbonic acid gas from rising above six parts in ten thousand.

Probably not one room in ten will meet this requirement. While only a fraction of a cubic foot of car-

bonic acid gas is thrown off by respiration, an ordinary small illuminating gas burner will throw off six cubic feet an hour. A natural gas stove, without chimney outlet, is one of the most pernicious air poisoners ever invented. It renders the air in an ordinary sized room unfit to breathe in a few minutes. The most efficient means of ventilation we have in the average home to-day is the old-fashioned fireplace. Provisions for the entrance of fresh and escape of foul air should be made near the floors and ceilings of every living room, in such a way as to avoid draughts. Permits for the erection of all buildings should specify that ample means be provided for ventilation, and official inspectors should see that the specifications are carried out. Electricity is to be the light and possibly the source of artificial heat in the near future.

The knowledge that we now possess of the pathology, the three essential factors of infection, the common sources of infection, the common routes of infection, the means at our command to prevent infection, ought and can stamp out, if acted on intelligently and promptly, more than one-half of the cases of tuberculosis in the next twenty-five years, and 90 per cent. of all cases in the coming century.

Sentiment in intelligent, sensible, respectable people can be aroused and cultivated. With the ignorant and vicious nothing succeeds like an absolute fiat.

\title{
H. H. HOLMES.
}

BY EUGENE S. TALBOT, M.D., D.D.S.

FELLOW OF THE CHICAGO ACADEXY OF MFDICINE.

That Herman Webster Mudgett, better known as H. H. Holmes, was a criminal par excellence is beyond doubt, but how far and in what respects he was a degenerate, in the accepted sense of the term, is worthy of serious consideration.

Few criminals have received more public attention, but despite this, many essential details of his history are wanting. Very little has been stated as to his heredity. He claims to have come from a respectable New England stock and to have been religiously and carefully brought up. As a boy he does not appear to have been a scapegrace, and no criminal charge is there on record against him. He married at 18 or 20 and commenced the study of medicine at Burlington, Vt. From there he went to the University of Michigan, where he claims to have graduated in medicine in 1884.

According to his own account, after graduating he taught school and practiced medicine in New Jersey for about a year, but it would appear that before this he had already, with a confederate, conspired to defraud life insurance companies, an industry he never entirely abandoned and which finally brought him to the gallows.

Just when he assumed the name of $\mathrm{H}$. H. Holmes is not certain, but probably not long after this. He himself says it was done when he went before the Illinois Pharmacy Board in 1886. From that time he has been known by that name and under it started in business as a druggist in the outskirts of Chicago, where he went into rather extensive and complicated transactions, chiefly of a crooked character. He managed, however, to keep in fair standing with his neighbors, and at one time was actively interested in church and religious matters.

During this time he had abandoned his New Hamp- 
shire wife and child, and without divorce, married in 1887 a Miss Belknap. Some years later in the same way he married a Miss Yoke in Denver under the name of Henry Mansfield Howard. $\mathrm{He}$ is supposed also to have contracted another bigamous marriage with Minnie Williams (one of his supposed victims). Beside these he had irregular relations with other women. In 1894, shortly before his final arrest for the murder of Pitzel, he revisited his old home and lived as husband for a few days with his first wife, to whom he told a romantic fiction anent his absence.

Between 1886 and 1894 there is no full account of his doings. They included an extensive series of swindles and forgeries. His transactions covered many parts of the country. He ranged from Canada to Texas and Colorado, often in trouble but generally managing in some way to escape the most serious consequences of his crimes. These were in their way often remarkable for their boldness and impudence. He negotiated for the sale to a gas company of a gas-

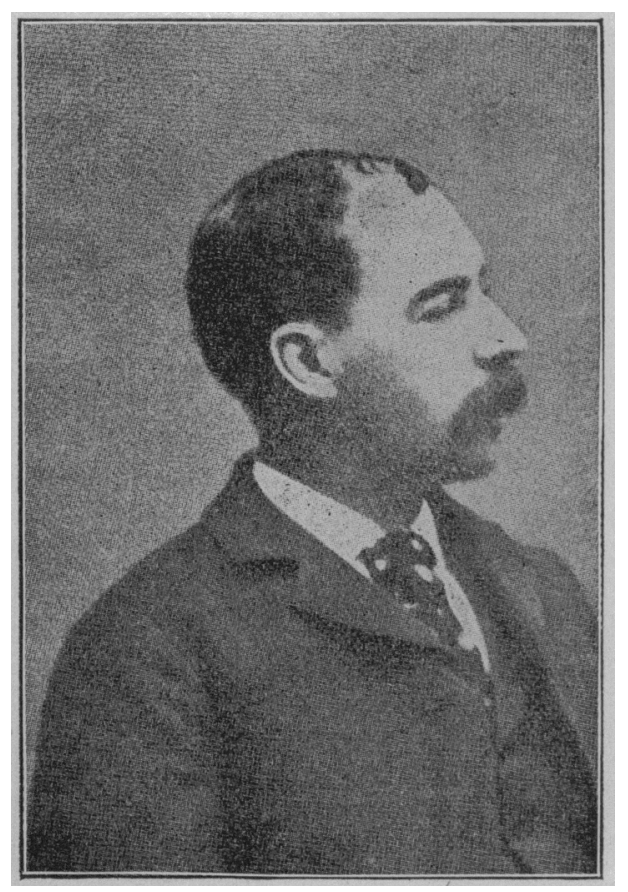

H. H. HOLMES.

making machine which was actually running on gas stolen from the company's own mains. He admits "deals of a somewhat similar nature."

While his confessions, generally, have been unreliable, it is probable that the above is safely inside the truth. He was emphatically a man of affairs, but his business transactions were so shady in their nature that the obscurity that enveloped them has been dispersed as yet only to give a glimpse such as the above.

It was during this period that he built his celebrated castle, with its secret chambers and passages, dark rooms, trapdoors, etc. Here he employed the female type-writers and other employes whose mysterious disappearance has done so much to make his popular reputation as a murderer. As far as this crime is concerned it must be admitted that the evidence against him is altogether circumstantial, his confessions and statements being notoriously and boastfully mendacious, in the main. Out of the twenty-seven murders he admitted in his latest confession shortly before his exe- cution, the majority of the victims are still living. Even his dying admission that he had been responsible for the sacrifice of two lives from criminal operations can not be accepted as perfectly reliable, considering his character for untruthfulness. He seems to have had little or no regard for human life, and as a dealer in "stiffs" and a defrauder of life insurance companies his operations were often enough suggestive of murders, even if these were not often committed.

The history of the Pitzel case, where it appears he made away with his confederate and then later with three of his children, and seemed to be planning the deaths of the widow and remaining family, distributing the deaths about the country in such a way as to avoid suspicion, must be fresh in the mind of the reader.

Holmes in his personal appearance, like Wainwright (whom he much resembled in his criminal career), presented nothing specially repulsive in his appearance. He was quiet, mild in manner and voice, fairly well educated, neat in dress and could pass anywhere for a respectuble business or professional man. During his long criminal career he appears to have had no particular ambition, except to succeed in his crooked operations and to ingratiate himself with women, for whom he seems to have had a more than normal inclination.

Mentally, there was no lack of acuteness. The fact that he managed to escape justice so long is an evidence of this. When he was finally arrested his behavior was peculiar and shifty. He told contradictory stories, and when his case came to trial he dismissed his lawyers and insisted on managing his own defense. Though he showed some aptness in examining witnesses, he was finally obliged to recall his counsel and give the case into his hands. The jury found him guilty almost without leaving the box. Perhaps the one witness whose testimony was most convicting was his latest bigamous wife.

Holmes made numerous statements and confessions to detectives and others and published a book while awaiting trial which purports to give an account of his life.

The most remarkable of these confessions, however, was that published in the Philadelphia Inquirer of April 12, three or four weeks prior to his execution. In this he reports the details of twenty-seven murders and claims that he was a case of acquired moral idiocy; that he presented numerous facial stigmata of degeneracy that had grown upon him, during his criminal career. Eighteen of the twenty-seven victims in this confession are living. Its author acknowledged its falsity within a day or two of its appearance.

It was not merely criminal vanity that prompted it, for he received for it a very substantial compensation of several thousand dollars. Throughout his imprisonment, his acquisitiveness was shown in this and other publications for which he received money, and in propositions of blackmail for persons he contemplated involving in these confessions.

While in Philadelphia, Jan. 30, 1896, I had the opportunity of making a careful physical examination of $\mathrm{H}$. H. Holmes, with the following results:

The subject was a 35 year old American, 5 feet $7 \frac{1}{2}$ inches in height, weighing 150 pounds. The occiput was asymmetrical and prominent, the bregma sunken and the left side of the forehead was more prominent than the right which was sloping. The hair was brown, and on body and face excessive. The face was 
arrested in development. The zygoma was arrested and hollowed on the right side.

The pictures of Holmes published in the daily papers and in his book, do not, to my mind, portray the features of the man as I saw him in his cell. Figure 1 , comes the nearest as he appeared when I saw him. His face was cleanly shaven, except moustache, very thin and much emaciated, presenting the appearance of being in a decline, due perhaps to confinement and a tendency to consumption. He had a cough, and the chances are if he had been allowed to remain in confinement he would have succumbed to tuberculosis.

Figures 2 and 3 show the antero-posterior and lateral shape of head. The right ear was lower than the left. The nose was long and very thin; stenosis of nasal bone very marked. The septum deflected to left, nose to the right. The thyroid gland was arrested. Strabismus in left eye, inherited. The left higher than the right. Slight protruding of the upper jaw; arrest of lower. The mouth on the left side drops lower than on the right. The width, outside of first molars was 2. Width outside first bicuspids 1.62. Height of vault, 63 .

Figures 4 and j̃ upper and lower jaw. The alveolar process was normal with the exception of the process about the second molar on right side which was hypertrophied. The teeth were normal in size and shape, the third molar undeveloped.

Marked pigeon breast, left side more prominent

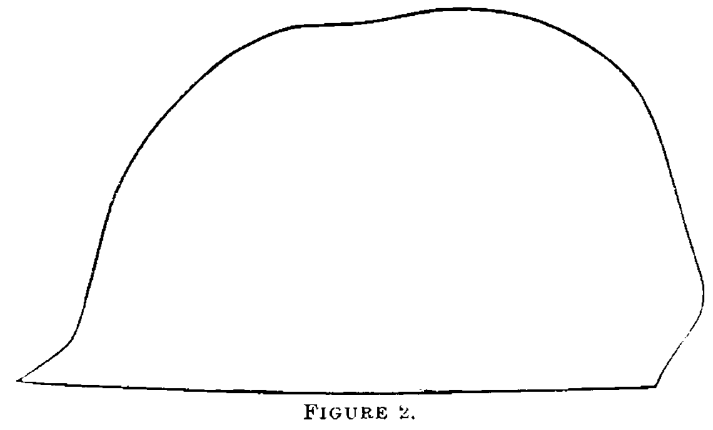

than right. Chest arrested with tendency to tuberculosis.

Arms: Right normal. Left one and one-half inches longer. He was right handed. His legs were long and thin. The tibia flattened. The feet medium in size but markedly deformed. Depression on left side of skull at bregma, said to be due to fall of brick at age of 30 . Sexual organs unusually small.

The jaws were unusually long as compared with the width, with a semi-saddle arch on the left side of the upper jaw. The molars of the lower jaw and left upper had been extracted in early life. The hypertrophy of the alveolar process, the want of development of the third molars and the general abnormal development certainly display a very unstable nervous system in his early life.

In twenty years' experience, I have never observed a more degenerate being from a physical standpoint. Holmes in his confession published, stated that ten years ago he was examined by four men of marked ability and by them pronounced mentally and physically normal and healthy. "To-day, I have every attribute of a degenerate a moral idiot." Is it possible that the crimes, instead of being the result of these abnormal conditions, are, in themselves, the occasion of degeneracy? . . . within the past few months these defects have increased with startling rapidity; as is made known to me by each succeeding examination," etc.
Holmes was examined ten years ago, not to ascertain stigmata but for life insurance, and the Bertillon system was not used at all since only criminals are thus examined, for identification. When these exam. inations are made, only one arm, finger and part of the body are measured, and not both sides for comparison.

While I was making my examination, I called his attention to a number of deformities which he was not aware he possessed.

Being a medically educated man, he certainly should have been better acquainted with these malformations, but he had evidently given this subject little attention since he was quite ignorant of the cause of two most marked deformities: The too deep depressions in the left frontal and occipital region of the head. These he claimed were due to a brick falling upon him at the age of 30 . The marked deformity of the chest walls he claimed to be due to pneumonia.

Both deformities were stigmata of degeneracy. Holmes, since his confinement, had no doubt lost flesh, which made these daformities appear more prominent. That they had developed as a result of his criminal tendencies is perfectly absurd. They must have developed with the osseous system, which would be complete by the 26 th year; nor will acromegaly account for them.

Holmes has been called an extraordinary criminal,

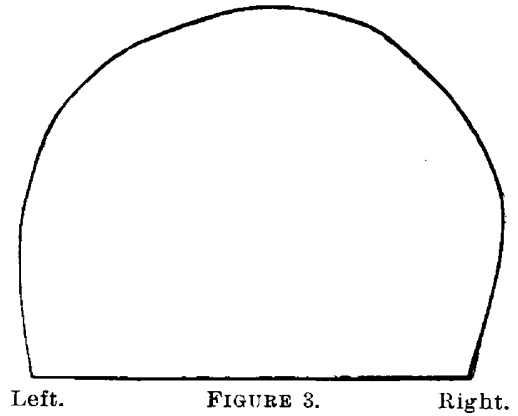

but he certainly was no more of a criminal than Wainwright,' who was well known in his time as an essayist and better as a forger and murderer. From the standpoint of literary and artistic culture Wainwright stood higher than Holmes. Like Holmes, he attempted to defraud insurance companies and there is no doubt he poisoned a girl for this purpose. Holmes' habitual criminality was modified by his education and antecedents. He had sufficient ability and self-control to successfully pass for a respectable citizen and to keep his criminal transactions so distributed as to territory and covered that only the self-interested perseverence of a life insurance company prompted by a hint from an ex-prison acquaintance could reveal them. His mental defects, so far as they existed, seem to have been confined to his moral sensibilities. He apparently had none of that sense of moral dictation which is a part of the constitution of every normal individual. He acted entirely as an egotist, perfectly capable of appreciating the possible immediate consequences of his acts and more than ordinarily expert in managing in. one way or another in avoiding them, but utterly licking in even the utilitarianism commonly expressed in the old adage that honesty is the best policy. While the murders have mainly created his popular reputation, they were but incidents in his consistent criminal career. $\mathrm{He}$ had

1 See Havelock Ellis' “The Criminal." p. 13. 
no regard for others' rights or lives. Doing away with a mistress or a confederate when she or he become inconvenient was an easy matter to him. His education, his dissecting-room training and subsequent specialty helped to remove original superstitious fears that might restrain the average criminal. $\mathrm{He}$ seems to have been utterly lacking in any lasting or sincere affection or attachment. A man who could deliberately desert successively two wives with their children would be capable of abandoning others whose relations were less intimate.

Havelock Ellis remarks ${ }^{2}$ that whatever refinement or tenderness of feeling criminals attain to reveals itself in what we should call sentiment or sentimentality. One of the characteristics of Wainwright's essays is their sentimentality. Himself, when in prison, he described as the possessor of "a soul whose nutriment is love, its offspring art, music, divine song and still holier philosophy." This sentimentality cropped up in Holmes in the letters to his first wife whose pathetic nature so impressed his counsel. It was also shown in his successes with women.
Holmes was certainly a degenerate physically, as the numerous stigmata he bore proved, but he was not more of one than many moral men and good citizens. There was, with the defects, undoubtedly a certain defectiveness and want of balance of the nervous system, but it can not be said that this necessitated the career he chose. If he were a "born criminal" it was not evident till after he had passed his minority and his moral imbecility did not apparently reveal itself to any very striking extent during his boyhood. He followed the course of many young men, who, on leaving the associations and restraints of home fall into evil courses, only he went farther and under pressure, it may be of want and misfortune, adopted to the fullest extent the anti-social and aberrant career of a criminal. There was, possibly, always a certain defect in his moral constitution which was checked in its effects by the restraints and training of his earlier years and might have been overcome entirely had his will been directed into proper paths. His case seems to be largely, if not altogether one of acquired moral obtuseness, not of complete congenital moral insanity.

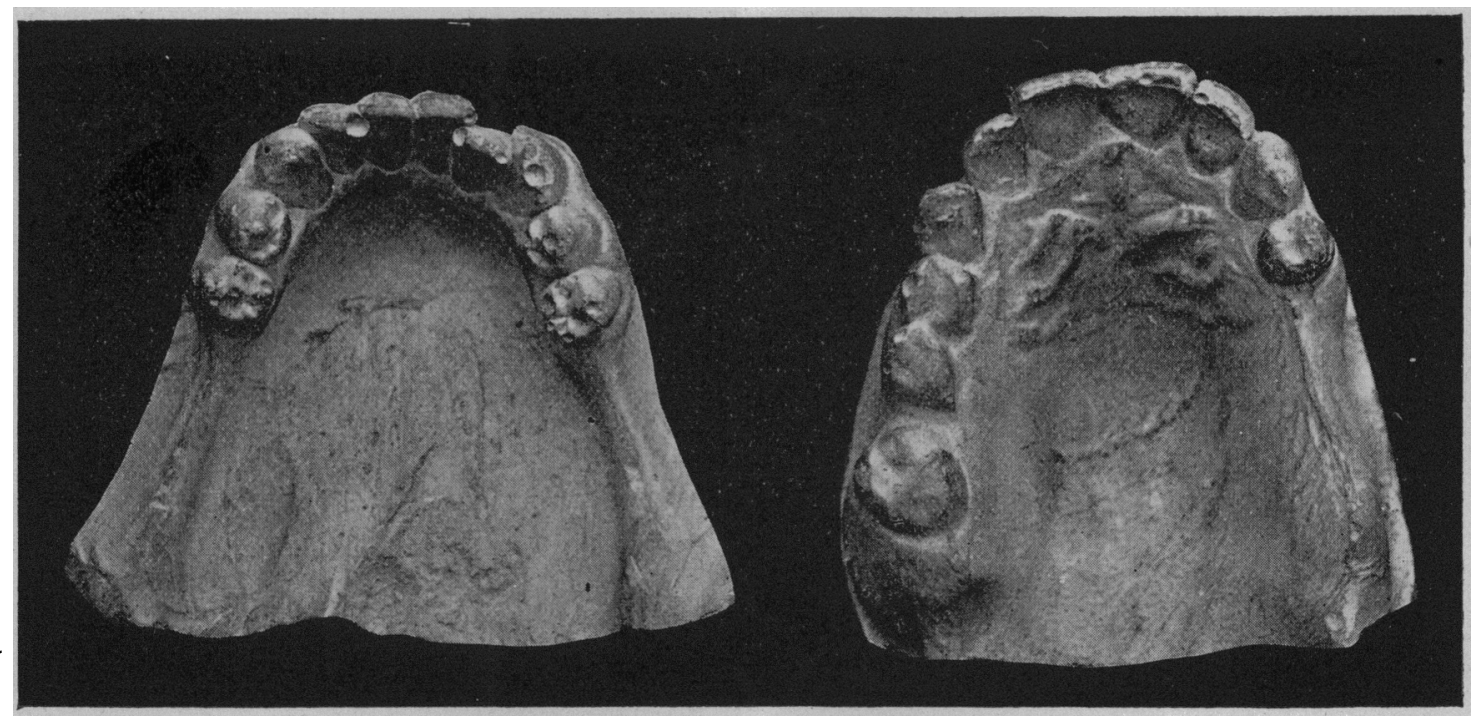

FIGURE 4.-Lower.

Figure 5.-Upper.

His crimes were apparently all deliberate and coldblooded. In his arrangement of his building, "The Castle," he made provisions for various kinds of crooked work. Only in this way can be reasonably explained this seemingly crazy piece of architecture. There is no evidence in his record that Holmes was insane in any way except it be morally.

In his apparent disregard for human life he was less peculiar than would at first sight seem. When a man has an object in view, which to him is a supreme motive, nothing will stand in his way. Holmes had no regard for the law if he could avoid its punishments, no conscientious scruples to govern his conduct. The taking of life was no more to him than to the Sultan of Turkey, a hanging judge or a military commandex, who will sacrifice a forlorn hope to gain an advantage. It is not so improbable, therefore, that he may have been a more or less wholesale murderer, if he found people in his way. He may have disposed of his victims and regarded it only as an inconvenient necessity. There is nothing in his character to make this intrinsically improbable. How far he was handicapped morally by his con-
stitution, is a question that can not be decided absolutely, but probably not more than the average criminal, who is generally of a more or less degenerate type.

It has been assumed that his vanity and egotism were excessive and evidence of his abnormal mental constitution. First, however. it ought to be proven that these existed to any such extent as is inferred. This can not well be done from his history. $\mathrm{He}$ was not obtrusive in his manner and his very choice of life made it impolitic, to say the least, to such publicity, and in his way he was very politic. $\mathrm{He}$ had ample confidence in himself, as was shown by his attempting his own defense. This may be taken as evidence of egotism, but he can hardly be said to have been obtrusively egotistic. His numerous statements in regard to himself were apparently not so much prompted by vanity as by a desire to make a profit from them. This was especially true of his last noted confession, which was one of the best remunerated productions of fiction based on fact that has been brought out in the country. 
There was certainly one striking psychologic peculiarity about the man; lying seemed to come naturally to him. He did it sometimes apparently without object. In this, however, he was not altogether unique, but there are marked examples, never in their acts passing over the line of legality.

Summing up the character of Holmes, we would say that he was, first of all, a swindler, a chevalier d'industrie and a roue. Money and women seemed to be his objects in life, especially the former, and he was perfectly unscrupulous in his methods of gratifying his ruling passions. His professional and general education, which he seems never after the first failure to have attempted to utilize properly, only served to make him the more dangerous and probably aided to make him a murderer as well as a seducer, bigamist, forger and thief. He may have had some congenital deficiency in his moral make-up, but the absolute lack of moral dictation of his later life, was due to or greatly aggravated by his self-chosen environments.

\section{TUBERCULOSIS OF THE MALE GENITAL ORGANS. \\ Read by title at the meeting of the American Surgical Association, at Detroit, Mich., May 26-28. 1896.}

BY NICHOLAS SENN, M.D., PH.D., LL.D.

PRESIDENT OF THE AMERICAN MEDICAL ASSOCIATION, ETC., ETC. SHICAGU.

(Concluded from page 18\%.)

Tuberculosis of the testicle and epididymis.Except in cases of acute diffuse miliary tuberculosis the essential organ of generation in man is seldom the seat of primary tuberculosis. On the other hand, primary localization of the tubercle bacillus not infrequently takes place in the epididymis, when the infection often extends from here to the testicle. There must be vascular conditions or other local predisposing causes which are concerned in determining hematogenous infection of a tubercilar nature in the epididymis which are absent or present to a lesser degree in the testicle. The epididymis is more often the seat of acute infective processes which prepare the soil for the bacillus of tuberculosis than the testicles which, to a certain extent, may explain the greater frequency with which primary tuberculosis occurs in the former than the latter. It must also be remembered that in descending tuberculosis from the upper portion of the urinary tract, the epididymis is exposed first to infection, and the patients often succumb to the primary disease and its complications before a sufficient time has elapsed for the testicle to become involved. There still prevails the greatest diversity of opinion among pathologists and surgeons in regard to the epididymis being most frequently affected in cases of urogenital tuberculosis.

Councilman (System of Surgery, Dennis, Vol. i, p. $246)$ believes that in such cases the most common seat of the primary disease is the epididymis. He says: "It may be confined to this or the testicle may be affected by continuity. The epididymis is converted into a more or less firm, caseous mass. From this the disease extends along the vas deferens, which becomes enlarged, and on section the interior is found to be lined with a whitish caseous tissue. In both the vas deferens and epididymis, the seat of the disease is primarily in the epithelium, and liter takes the form of a tubercular inflammation. Seminal vesicles on the same side become affected in most cases, or they may be passed by and the disease appear in the prostate or bladder. Up to this point it is easy to see how the infection has taken place. The extension has been in the direction of the secretion, and the bacilli could be carried along with the secretion. From the bladder the extension is in a direction opposite to the flow of the secretion; with or without any involvement of the ureter, infection of the pelvis of the kidney and of the adjoining kidney tissue takes place. It is probable that the bacilli find suitable conditions for growth in the ureter and grow along the walls, just as on the surface of a solid medium, until the pelvis of the kidney is reached. There is no other way for infection to take place from the bladder to the kidney than along the ureter. There is no lymphatic or vascular connection. The proof that this is the usual route of infection in genito-urinary tuberculosis is shown by the certainty with which the disease can be traced step by step, and the extreme rarity of the disease in females as compared with males. In some, cases the disease appears to be primary in the kidney and the infection may take place in an opposite direction."

My clinical experience corresponds with the views of Councilman that in more than 50 per cent. of urogenital tuberculosis the disease has its primary starting point in the epididymis.

We shall see in considering the etiology of this disease that there are many authorities who take the opposite ground and affirm that urogenital tuberculosis most frequently has its origin in the upper portion of the urinary tract.

Etiology.-Aievoli (Eriberto sur la tuberculosi di testiculo ed epididimo. Morgagni, p. 65̃7, p. 728, 1891) made experiments on guinea pigs by injecting into the testicle and epididymis tubercular material and pure cultures of the tubercle bacillus. Only in one case did he find tubercle bacilli in the lumen of the seminal ducts, but in all instances there was produced an inter-canalicular proliferation, so that the walls of the canals were perforated and large masses with caseous centers were found in which pseudo giant cells could be demonstrated. In some places an attempt at cure by sclerosis could be found at the same time, also tubercle production in the vicinity of blood vessels and the interstitial tissue. He believes that such an inter-canalicular tuberculosis is possible without direct inoculation, as the bacilli may reach the interstitial tissue through the lymph stream. The results of these experimental reseaches are closely allied with the observations of pathologists concerning the gross pathologic anatomy of testicular tuberculosis. The disease in the epididymis is caused frequently by a descending infection from the prostate and seminal vesicles, but it may originate in the epididymis primarily, as tubercle bacilli have been found on several occasions in the seminal ducts in healthy testicles in phthisical subjects. The process begins in most cases in the epididymis in the form of conglomerate tubercles which are conspicuous for the number and size of the giant cells. The tubercle elements are derived mostly from the interstitial connective tissue, but part of the product may be furnished by the epithelial cells and other tissues of the seminal ducts. Infection may extend along the urogenital canal from the kidney to the testicle; as a rule, however, tuberculosis of the testicle begins in the epididymis. Sometimes the testicle and epididymis are affected simultaneously in cases of general miliary tuberculosis. "The fact that the spermatic. 